\title{
Synthesis of Amino-functionalized Waste Wood Flour Adsorbent for High-capacity Pb (II) Adsorption
}

Yi Tan ${ }^{\mathrm{a}}$, Kaili Wang ${ }^{\mathrm{a}}$, Qian Yan ${ }^{\mathrm{a}}$, Shifeng Zhanga,*, Jianzhang $\mathrm{Li}^{\mathrm{a}, *}$ and Yong Ji ${ }^{\mathrm{b}}$

${ }^{\text {a }}$ College of Material Science and Technology, MOE Key Laboratory of Wooden

Material Science and Application, Beijing Forestry University, Beijing 100083, China

${ }^{\mathrm{b}}$ College of Water Conservancy and Ecological Engineering, Nanchang Institute of

Technology, Nanchang 330099, China

*E-mail: shifeng.zhang@bjfu.edu.cn. Phone /Fax: +86 01062336072 (S.Z.).

*E-mail: lijzh@bjfu.edu.cn (J.L.). 


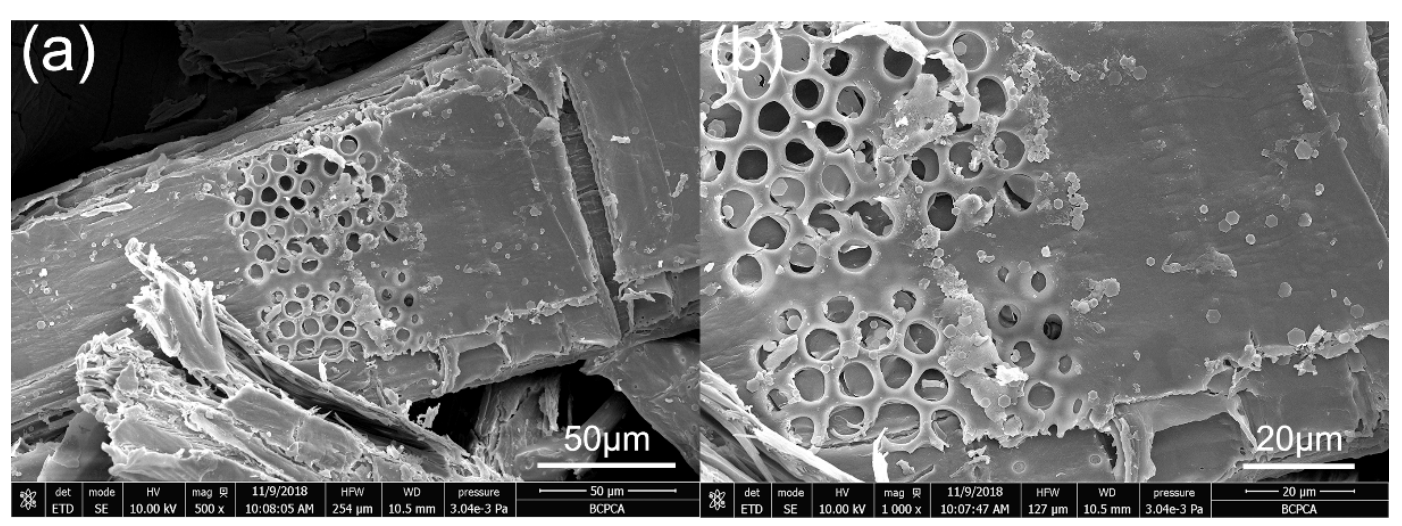

Figure S1. FE-SEM observations around wood pit of DWF- $\mathrm{NH}_{2}$ (a) with a scale bar of $50 \mu \mathrm{m}$,

(b) with a scale bar of $20 \mu \mathrm{m}$.
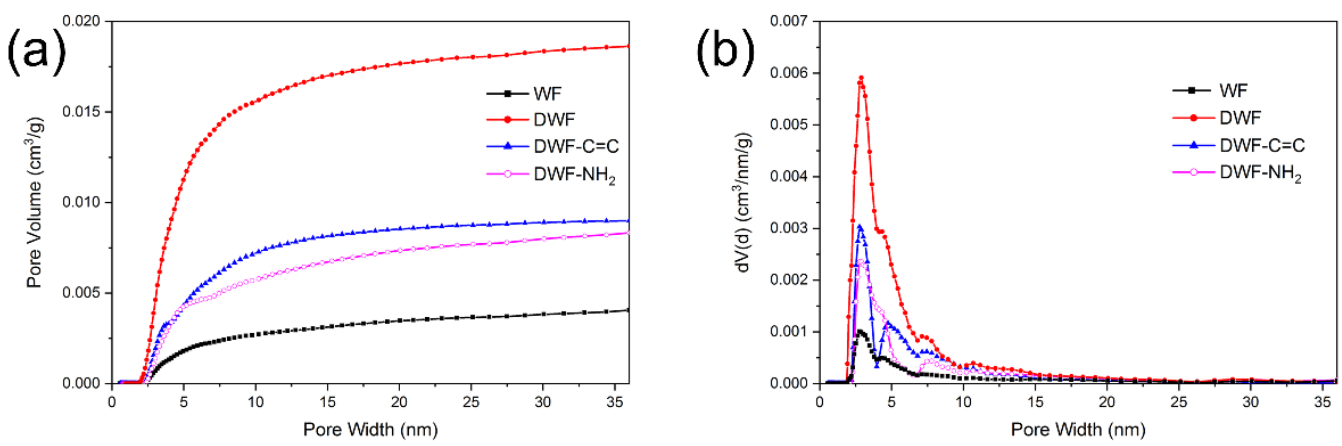

Figure S2. (a) Pore volume curves as a function of pore diameter and (b) pore diameter

distribution curves of WF, DWF, DWF-C=C, and DWF- $\mathrm{NH}_{2}$ (P/Po used: 0.99407, 0.99408,

0.99921 and 0.99890 , respectively).

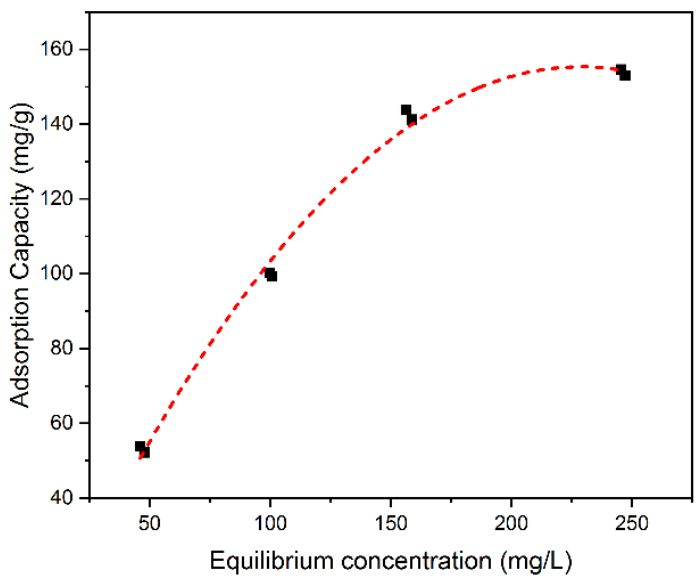

Figure S3. Isotherms of $\left(q_{e}\right) \mathrm{Pb}$ equilibrium adsorbed amount with $\left(C_{e}\right)$ equilibrium concentration. 


\section{Kinetics study on metal ion adsorption of $\mathrm{DWF}-\mathrm{NH}_{2}$ adsorbents}

To investigate the kinetics of the adsorption process, the pseudo-first-order model (Equation (1))

and the pseudo-second-order model (Equation (2)) were used to fit the experimental data.

$$
\begin{aligned}
& \ln \left(q_{e}-q_{t}\right)=\ln q_{e}-k_{1} t \\
& \frac{d q}{d t}=k_{2}\left(q_{e}-q\right)^{2} \\
& k_{0}=k_{2} q_{e}^{2}
\end{aligned}
$$

where $q_{e}(\mathrm{mg} / \mathrm{g})$ is the equilibrium adsorption capacity and $q_{t}(\mathrm{mg} / \mathrm{g})$ is the adsorption capacity at

time $t(\min ) ; k_{1}\left(\min ^{-1}\right)$ is the pseudo-first-order rate constant; and $k_{2}\left(\mathrm{~g} / \mathrm{mg} \cdot \mathrm{min}^{-1}\right)$ is the pseudosecond-order rate constant. For the pseudo-second-order kinetics model, when $t$ approaches 0 , the initial adsorption rate $k_{0}$ could be defined using Equation (3).

\section{Adsorption isotherms of metal ion adsorption of $\mathrm{DWF}-\mathrm{NH}_{2}$ adsorbents}

The adsorption process was fitted using the Langmuir (Equation (4)), Freundlich (Equation (5)), and Temkin (Equation (6)) models. The Langmuir model is an ideal adsorption formula, which assumes that the active sites are uniform, and the adsorbents are homogeneous without interaction between them, then the adsorption could achieve balance in a single molecular layer. The constant $R_{L}$ expressed as Equation (7) was calculated using the Langmuir model. $R_{L}$ could be used to effectively evaluate whether the adsorption isotherm process is favorable $\left(0<R_{L}<1\right)$ or unfavorable $\left(R_{L}>1\right)$. The Freundlich model indicates that the physical adsorption occurred during adsorption because of the rough and irregular surface structure of the adsorbent, leading to multilayer physical adsorption. The Temkin model suggested the presence of strong interactions between the adsorbed metals and the adsorbent during adsorption ${ }^{16}$. 


$$
\begin{aligned}
& q_{e}=q_{\max }+q_{\max } \frac{K_{L} C_{e}}{1+K_{L} C_{e}} \\
& q_{e}=K_{F} C_{e}^{1 / n} \\
& q_{e}=\frac{R T}{b_{T}} \ln \left(A_{T} C_{e}\right) \\
& R_{L}=1 /\left(1+K_{L} C_{0}\right)
\end{aligned}
$$

In these equations, $q_{e}(\mathrm{mg} / \mathrm{g})$ is the amount of metal ions adsorbed at the equilibrium; $C_{e}(\mathrm{mg} / \mathrm{L})$ is the concentration of metal ions in the solution at the equilibrium; $K_{L}$ is the Langmuir constant (L/mg); $R_{L}$ is a constant; $C_{0}$ is the initial concentration of metal ions in the solution; $K_{F}$ and $1 / n$ are the Freundlich constants related to the capacity and intensity of the adsorption, respectively; $A_{T}(\mathrm{~L} / \mathrm{g})$ is the Temkin equilibrium constant; $b_{T}$ is the Temkin constant associated with the adsorption heat; $R(8.314 \mathrm{~J} / \mathrm{mol})$ is the gas constant; and $T(\mathrm{~K})$ is the absolute temperature.

\section{Competitive adsorption experiments}

The selectivity coefficient $k$ is calculated according to Equation (8).

$$
k=\frac{q_{x} / q^{\prime}}{C_{x} / C^{\prime}}
$$

where $q_{x}(\mathrm{mg} / \mathrm{g})$ is the adsorption capacity of $\mathrm{X}$ ions in the mixed solution, and $q^{\prime}(\mathrm{mg} / \mathrm{g})$ is the total adsorption capacity of the rest of the metal ions in the mixed solution, $C_{x}(\mathrm{mg} / \mathrm{g})$ is the initial concentration of $\mathrm{X}$ ions in the mixed solution, and $C^{\prime}(\mathrm{mg} / \mathrm{g})$ is the initial concentration of the rest of the metal ions in the mixed solution. 